\title{
Let-7b-5p promotes cell apoptosis in Parkinson's disease by targeting HMGA2
}

\author{
YUJING HUANG, YING LIU, JING HUANG, LU GAO, ZHENGGANG WU, LU WANG and LIN FAN \\ Department of Neurology, Taizhou People's Hospital, Taizhou, Jiangsu 225300, P.R. China
}

Received November 6, 2020; Accepted February 19, 2021

DOI: $10.3892 / \mathrm{mmr} .2021 .12461$

\begin{abstract}
Parkinson's disease (PD), a common multifactorial neurodegenerative disease, is characterized by irreversible loss of dopaminergic neurons in the substantia nigra. In-depth study of the pathogenesis of PD is of great importance. High-mobility group AT-hook 2 (HMGA2) has been proposed to be implicated with neuronal differentiation and impairment of cognitive function. However, whether HMGA2 plays a role in PD is rarely explored. In the present study, N-methyl-4-phenyl-1,2,3,6-tetrahydropyridine (MPTP)-treated PD mice models and N-methyl-4- phenylpyridinium $\left(\mathrm{MPP}^{+}\right)$-treated SH-SY5Y cell models were established. Reverse transcription-quantitative PCR showed that HMGA2 displayed low levels in brain tissues of MPTP-treated mice and $\mathrm{MPP}^{+}$-treated SH-SY5Y cells. Moreover, HMGA2 overexpression suppressed SH-SY5Y cell apoptosis. Additionally, let-7b-5p bound with HMGA2 3' untranslated region (UTR), and its expression was negatively correlated with HMGA2 level. Moreover, let-7b-5p presented high levels in brain tissues of PD mice and MPP ${ }^{+}$-treated SH-SY5Y cells, and knockdown of let-7b-5p inhibited SH-SY5Y cell apoptosis. Rescue assays illustrated that HMGA2 neutralized the promotive effects of let-7b-5p mimics on SH-SY5Y cell apoptosis. In conclusion, the present study demonstrated that let-7b-5p contributes to cell apoptosis in PD by targeting HMGA2, which offers a potential theoretical basis for the study of effective therapy in PD.
\end{abstract}

\section{Introduction}

Parkinson's disease (PD) is a multifactorial neurodegenerative disease influencing 7-10 million individuals globally, and its incidence ranks second only to Alzheimer's disease (1). Clinically, patients with PD at the early stage are prone to cognitive decline, especially executive function deficits (2).

Correspondence to: Dr Yujing Huang, Department of Neurology, Taizhou People's Hospital, 366 Taihu Road, Medical High-tech Zone, Taizhou, Jiangsu 225300, P.R. China

E-mail: huangyjtz@hotmail.com

Key words: let-7b-5p, high-mobility group AT-hook 2, Parkinson's disease, cell apoptosis
PD affects men twice more often than women $(3,4)$. Static tremor, stiffness and postural distortion are common clinical manifestations of PD (5). Pathologically, the progressive and irreversible loss of dopaminergic neurons were widely observed in the substantia nigra (6). In addition, it was reported that PD is regulated by genetic and environmental factors $(1,7)$. Unfortunately, PD is unable to be cured until now and the existing treatment methods for PD have limited efficacy (8). Therefore, a further study of the molecular mechanism underlying PD progression is of great importance.

MicroRNAs (miRNAs), a subclass of non-coding RNAs, are fundamental regulatory elements of gene expression by targeting mRNAs for cleavage or translational inhibition (9). miRNAs are post-transcriptional modulators via sequence complementarity to the untranslated regions (UTRs) or the coding sequences of target mRNAs (10). Let-7b-5p was identified as a biomarker of various nervous system diseases including ischemic stroke, Parkinsonian syndromes and Alzheimer's disease (11-13). However, the potential mechanisms of let-7b-5p in PD have not been explored.

High-mobility group AT-hook 2 (HMGA2) protein, a member of the non-histone chromosomal high mobility group (HMG) protein family (14), is located at human chromosomal band 12q14-15 (15) and mouse chromosome 10 (16). HMGA2 mediates the expression of specific genes mainly by AT-hook motif via cooperating with other DNA-binding activities to regulate chromatin structure and transcription (14). Previously, HMGA2 was reported to promote self-renewal of neural stem cells in young mice, and the decline in HMGA2 level during aging may contribute to neural stem cell dysfunction (17). HMGA2 plays a functional role in deciding the differentiation of human neural progenitors to neurons or glial cells (18). HMGA2 was identified to promote proliferation of mouse neurosphere cells (19). In addition, HMGA2 was reported to be involved in the pathogenesis of Alzheimer's disease, a neurodegenerative disease, by affecting intracranial volume $(20,21)$. However, the role of HMGA2 in PD was rarely explored.

In the present study, it was hypothesized that HMGA2 plays a neuroprotective role in PD. HMGA2 was identified to be downregulated in in vitro and in vivo models of $\mathrm{PD}$. The specific role of HMGA2 on apoptosis in PD and its potential mechanism were subsequently investigated. The results of the present study might offer a potential theoretical basis for the study of effective therapy in PD. 


\section{Materials and methods}

Bioinformatics analysis. According to the StarBase website (http://starbase.sysu.edu.cn/), 10 miRNAs (hsa-let-7b-5p, hsa-let-7f-5p, hsa-miR-196b-5p, hsa-let-7d-5p, hsa-let-7i-5p, hsa-miR-4458, hsa-let-7a-5p, hsa-miR-196a-5p, hsa-let-7g-5p and hsa-let-7e-5p) were identified to target HMGA2.

Animals. The male C57BL/6 mice ( $\mathrm{n}=30,10$-week-old, 20-25 g) were obtained from Chinese Academy of Medical Sciences Laboratory Animal Center (Beijing, China) and kept in individual cages under a 12-h light/dark cycle with standard pellet chow and water. The animal experiments were conducted based on the protocols from Research Committee, and the study was authorized by the Institutional Animal Care and Use Committee of Taizhou People's Hospital (approval no. 2019-004; Jiangsu, China).

N-methyl-4-phenyl-1,2,3,6-tetrahydropyridine (MPTP) mice model. For MPTP mice model establishment, mice $(\mathrm{n}=24)$ were intraperitoneally injected daily with $30 \mathrm{mg} / \mathrm{kg}$ free base MPTP-HCl (Sigma-Aldrich; Merck KGaA) for 4 consecutive days. Mice $(n=6)$ in the sham group were injected with an equivalent volume of $0.9 \%$ sterile saline (Sigma-Aldrich; Merck KGaA). After the last injection of MPTP for 1, 3, 5 and 7 days, mice were sacrificed, decapitated and the brain tissues were collected and stored at $-80^{\circ} \mathrm{C}$ for further study.

Cell culture and treatment. SH-SY5Y cells purchased from SUNNCELL (cat. no. C191) were cultured in DMEM (Gibco; Thermo Fisher Scientific, Inc.) containing 10\% FBS (Gibco; Thermo Fisher Scientific, Inc.), penicillin (100 U/ml) and streptomycin $(100 \mu \mathrm{g} / \mathrm{ml})$ with $5 \% \mathrm{CO}_{2}$ at $37^{\circ} \mathrm{C}$ in a humidified atmosphere. For cell treatment, $\mathrm{MPP}^{+}$(Sigma-Aldrich; Merck KGaA) was supplemented into the cultures to a final concentration of $0.25,0.5$ and $1 \mathrm{nM}$ for $24 \mathrm{~h}$. Cells in the control group were treated with normal saline (Sigma-Aldrich; Merck KGaA).

Cell transfection. Let-7b-5p inhibitor (30 nM; Shanghai GenePharma Co., Ltd.) and mimics (30 nM; Shanghai GenePharma Co., Ltd.) were used to knock down and overexpress let-7b-5p, respectively. NC mimics ( $30 \mathrm{nM}$; Shanghai GenePharma Co., Ltd.) served as the negative control for let-7b-5p mimics, while NC inhibitor (30 nM; Shanghai GenePharma Co., Ltd.) served as the negative control for let-7b-5p inhibitor. The following sequences were included in the present study: let-7b-5p mimics, 5'-UGAGGUAGUAGGUUGUGUGGUU-3'; NC mimics, GGUUAGUUAUUUGGUGUGGAGG; let-7b-5p inhibitor, 5'-AACCACACAACCUACUACCUCA-3'; and NC inhibitor, CCUCCACACCAAAUAACUAACC. The full length of HMGA2 was inserted into empty pcDNA3.1 vector $(2 \mu \mathrm{g})$ to overexpress HMGA2 with the empty pcDNA3.1 vector as the NC. All vectors (GeneChem, Inc.) were transfected into SH-SY5Y cells at room temperature for $48 \mathrm{~h}$ using Lipofectamine RNAiMAX (Invitrogen; Thermo Fisher Scientific, Inc.). The time interval between transfection and subsequent experimentation was $48 \mathrm{~h}$.

Western blot analysis. Total protein from brain tissues and SH-SY5Y cells was extracted with radioimmunoprecipitation assay buffer (Beyotime Institute of Biotechnology). The protein concentration was determined using the BCA Protein Assay kit (Beyotime Institute of Biotechnology). Equal protein $(20 \mu \mathrm{g} / \mathrm{lane})$ was subjected to $10 \%$ sodium dodecyl sulfate polyacrylamide gel electrophoresis and transferred to polyvinylidene fluoride membranes. After being blocked with $5 \%$ fat-free milk for $2 \mathrm{~h}$ at room temperature, the membranes were then incubated with primary antibodies at $4^{\circ} \mathrm{C}$ overnight. After that, a horseradish peroxidase-conjugated secondary antibody (cat. no. ab6721; 1:5,000; Abcam) was applied to incubate the membranes at room temperature for $2 \mathrm{~h}$. Finally, the ECL Detection kit (Cytvia) was used to detect the protein signals. The primary antibodies used were HMGA2 (cat. no. ab273014; 1:500; Abcam), Bax (cat. no. ab32503; 1:500; Abcam), Bcl-2 (cat. no. ab182858; 1:500; Abcam) and GAPDH (cat. no. ab128915; 1:500; Abcam). The protein bands were semi-quantified using ImageJ version 1.51 software (National Institutes of Health).

Flow cytometry analysis. An Annexin V-fluorescein isothiocyanate (FITC) cell apoptosis kit (Invitrogen; Thermo Fisher Scientific, Inc.) was applied to detect SH-SY5Y cell apoptosis. In short, after transfection with indicated plasmids for $48 \mathrm{~h}$, SH-SY5Y cells $(10,000)$ were harvested and fixed by $4 \%$ formaldehyde at room temperature for $30 \mathrm{~min}$. SH-SY5Y cells were then permeabilized using $0.2 \%$ Triton X-100 in PBS (Sigma-Aldrich; Merck KGaA) for $5 \mathrm{~min}$ at room temperature. Subsequently, cells were incubated with $5 \mu$ l Annexin V-FITC and $5 \mu \mathrm{l}$ propidium iodide at room temperature for $10 \mathrm{~min}$ in the dark. Finally, the apoptosis rate of SH-SY5Y cells was analyzed by a BD FACSCalibur flow cytometry (BD Biosciences) using CellQuest software (version 3.0; BD Biosciences). Early apoptosis was assessed using the following formula: Cell apoptosis rate $=$ number of cells in quadrant $3 /$ number of cells in all quadrants.

Terminal deoxynucleotidyl transferase-mediated dUTP nick end labeling (TUNEL) staining. SH-SY5Y cells $\left(2 \times 10^{4}\right)$ were plated onto coverslips in 24-well plates. Then, the coverslips were fixed with $4 \%$ paraformaldehyde for $30 \mathrm{~min}$ and permeabilized for $10 \mathrm{~min}$ using $20 \mu \mathrm{g} / \mathrm{ml}$ proteinase $\mathrm{K}$ (Beijing Solarbio Science \& Technology Co., Ltd.) at $27^{\circ} \mathrm{C}$. Then, the samples were placed in a TUNEL detection kit (Beyotime Institute of Biotechnology) to be stained by $50 \mu \mathrm{l}$ TUNEL at $37^{\circ} \mathrm{C}$ for $1 \mathrm{~h}$ and followed by washing with PBS three times. The cell nucleus was dyed using DAPI (1:100) at room temperature for $10 \mathrm{~min}$. TUNEL cells were stained green and cell nuclei (DAPI) were stained blue. Finally, the images were observed under a fluorescence microscope (magnification, x100; BX51TRF; Olympus Corporation) from five randomly selected visual fields. Quant Center 2.1 software (3DHISTECH Ltd.) was used to analyze the images. The ratio of TUNEL staining positive cells to total DAPI staining positive cells was defined as the apoptosis rate.

$R N A$ extraction and reverse transcription-quantitative polymerase chain reaction ( $R T-q P C R)$ analyses. Total RNA was extracted from brain tissues and SH-SY5Y cells using TRIzol reagent (Invitrogen; Thermo Fisher Scientific, Inc.). Total RNA was reverse transcribed into cDNA with a TransScript miRNA First-Strand cDNA Synthesis SuperMix (TransGen Biotech Co., Ltd.) or RevertAid RT Reverse Transcription kit (Thermo 
Table I. Sequence of primers used for reverse transcriptionquantitative PCR.

\begin{tabular}{|c|c|}
\hline Gene (species) & Sequences $\left(5^{\prime} \rightarrow 3^{\prime}\right)$ \\
\hline $\begin{array}{l}\text { let-7b-5p } \\
\text { (human) }\end{array}$ & $\begin{array}{l}\text { F: GCGCTGAGGTAGTAGGTT } \\
\text { R: GTGCAGGGTCCGA }\end{array}$ \\
\hline $\begin{array}{l}\text { let-7b-5p } \\
\text { (mice) }\end{array}$ & $\begin{array}{l}\text { F: 5TGAGGTAGTAGGTTGTGTGGTTATAGC } \\
\text { R: CTCTACAGCTATATTGCCAGCCAC }\end{array}$ \\
\hline $\begin{array}{l}\text { U6 } \\
\text { (human) }\end{array}$ & $\begin{array}{l}\text { F: AAAGCAAATCATCGGACGACC } \\
\text { R: GTACAACACATTGTTTCCTCGGA }\end{array}$ \\
\hline $\begin{array}{l}\text { U6 } \\
\text { (mice) }\end{array}$ & $\begin{array}{l}\text { F: CGCTTCGGCAGCACATATAC } \\
\text { R: TTCACGAATTTGCGTGTCAT }\end{array}$ \\
\hline $\begin{array}{l}\text { HMGA2 } \\
\text { (human) }\end{array}$ & $\begin{array}{l}\text { F: AAGAAAGCAGAAGCCACTG } \\
\text { R: TCAGTTTCCTCCTGAGCAG }\end{array}$ \\
\hline $\begin{array}{l}\text { HMGA2 } \\
\text { (mice) }\end{array}$ & $\begin{array}{l}\text { F: CCCTCTCCTAAGAGACCCA } \\
\text { R: CTCTGCTTTCTTCTGGGCT }\end{array}$ \\
\hline $\begin{array}{l}\text { GAPDH } \\
\text { (human) }\end{array}$ & $\begin{array}{l}\text { F: TCAAGATCATCAGCAATGCC } \\
\text { R: CGATACCAAAGTTGTCATGGA }\end{array}$ \\
\hline $\begin{array}{l}\text { GAPDH } \\
\text { (mice) }\end{array}$ & $\begin{array}{l}\text { F: CAAGGAGACCTCAAGGTCAG } \\
\text { R: TACGGCCAAATCAGAGGTG }\end{array}$ \\
\hline $\begin{array}{l}\text { hsa-let-7f-5p } \\
\text { (human) }\end{array}$ & $\begin{array}{l}\text { F: TGAGGTAGTAGATTGTATAGTTTGGG } \\
\text { R: CTCTACAGCTATATTGCCAGCCAC }\end{array}$ \\
\hline $\begin{array}{l}\text { hsa-miR-196b-5p } \\
\text { (human) }\end{array}$ & $\begin{array}{l}\text { F: TAGGTAGTTTCCTGTTGTTGGG } \\
\text { R: CTCTACAGCTATATTGCCAGCCAC }\end{array}$ \\
\hline $\begin{array}{l}\text { hsa-let-7d-5p } \\
\text { (human) }\end{array}$ & $\begin{array}{l}\text { F: AGAGGTAGTAGGTTGCATAGTT } \\
\text { R: CTCTACAGCTATATTGCCAGCCAC }\end{array}$ \\
\hline $\begin{array}{l}\text { hsa-let-7i-5p } \\
\text { (human) }\end{array}$ & $\begin{array}{l}\text { F: TGAGGTAGTAGTTTGTGCTGTT } \\
\text { R: CTCTACAGCTATATTGCCAGCCAC }\end{array}$ \\
\hline $\begin{array}{l}\text { hsa-miR-4458 } \\
\text { (human) }\end{array}$ & $\begin{array}{l}\text { F: AGAGGTAGGTGTGGAAGAA } \\
\text { R: CTCTACAGCTATATTGCCAGCCAC }\end{array}$ \\
\hline $\begin{array}{l}\text { hsa-let-7a-5p } \\
\text { (human) }\end{array}$ & $\begin{array}{l}\text { F: TGAGGTAGTAGGTTGTATAGTT } \\
\text { R: CTCTACAGCTATATTGCCAGCCAC }\end{array}$ \\
\hline $\begin{array}{l}\text { hsa-miR-196a-5p } \\
\text { (human) }\end{array}$ & $\begin{array}{l}\text { F: TAGGTAGTTTCATGTTGTTGGG } \\
\text { R: CTCTACAGCTATATTGCCAGCCAC }\end{array}$ \\
\hline $\begin{array}{l}\text { hsa-let-7g-5p } \\
\text { (human) }\end{array}$ & $\begin{array}{l}\text { F: TGAGGTAGTAGTTTGTACAGTT } \\
\text { R: CTCTACAGCTATATTGCCAGCCAC }\end{array}$ \\
\hline $\begin{array}{l}\text { hsa-let-7e-5p } \\
\text { (human) }\end{array}$ & $\begin{array}{l}\text { F: TGAGGTAGGAGGTTGTATAGTT } \\
\text { R: CTCTACAGCTATATTGCCAGCCAC }\end{array}$ \\
\hline
\end{tabular}

F, forward; R, reverse; miR, microRNA; HMGA2, high-mobility group AT-hook 2.

Fisher Scientific, Inc.) at $37^{\circ} \mathrm{C}$ for $60 \mathrm{~min}$ and $85^{\circ} \mathrm{C}$ for $1 \mathrm{~min}$. RT-qPCR was conducted on an Applied Biosystems 7500 Real-Time PCR System (Applied Biosystems; Thermo Fisher Scientific, Inc.) using PowerUp ${ }^{\mathrm{TM}} \mathrm{SYBR}^{\mathrm{TM}}$-Green Master Mix (Thermo Fisher Scientific, Inc.). The thermocycling conditions were as follows: $95^{\circ} \mathrm{C}$ for $20 \mathrm{sec}$; followed by 39 cycles of $58^{\circ} \mathrm{C}$ for $20 \mathrm{sec}$ and $68^{\circ} \mathrm{C}$ for $30 \mathrm{sec}$. GAPDH and U6 were applied as internal controls for HMGA2 and miRNAs, respectively. All the data were calculated according to the $2^{-\Delta \Delta \mathrm{Cq}}$ method (22). Primer sequences are listed in Table I.

RNA immunoprecipitation(RIP) assay.RIPassay wasconducted with a Magna RNA-binding protein immunoprecipitation kit
(EMD Millipore). Briefly, SH-SY5Y cells were co-cultured overnight at $4{ }^{\circ} \mathrm{C}$ with magnetic beads pre-coated with anti-Argonaute2 (anti-Ago2; cat. no. ab32381; Abcam) and anti-Immunoglobulin G (anti-IgG; cat. no. ab205718; Abcam). Finally, RT-qPCR was employed to assess the relative enrichment of HMGA2 and let-7b-5p.

Bioinformatics analysis. The TargetScan version 7.2 (http://www.targetscan.org/vert_72/) tool was used to reveal the miRNAs that have a binding position on HMGA2 3'-UTR.

Luciferase reporter assay. The wild type (WT) or mutant (Mut) 3'-UTR fragment from HMGA2 was cloned into the pmirGLO dual-luciferase vector (Promega Corporation) to construct pmirGLO-HMGA2 3'-UTR-WT (1 $\mu \mathrm{g})$ or pmirGLO-HMGA2 3'-UTR-Mut (1 $\mu \mathrm{g})$ plasmids. PmirGLO-HMGA2 3'-UTR-Mut served as the negative control for pmirGLO-HMGA2 3'-UTR-WT. Then, the pmirGLO-HMGA2 3'-UTR-WT or pmirGLO-HMGA2 3'-UTR-Mut vectors were co-transfected into SH-SY5Y cells with NC mimics or let-7b-5p mimics using Lipofectamine $2000^{\circledR}$ reagent (Invitrogen; Thermo Fisher Scientific, Inc.) at $37^{\circ} \mathrm{C}$ for $48 \mathrm{~h}$. The luciferase activity was examined with a Dual-Luciferase Reporter Assay System (Promega Corporation) $48 \mathrm{~h}$ after transfection and was calculated as the ratio of firefly to Renilla luciferase activity.

Caspase-3 activity analysis. The caspase-3 activity was detected by use of the caspase-3 assay kit (R\&D Systems, Inc.). In detail, $\mathrm{SH}-\mathrm{S} Y 5 \mathrm{Y}$ cells were lysed and centrifuged at $300 \mathrm{x} \mathrm{g}$ for $10 \mathrm{~min}$ at $4^{\circ} \mathrm{C}$ to collect supernatants. A BCA Protein Assay kit (Beyotime Institute of Biotechnology) was used to quantify the protein concentrations of each sample. Then, the supernatants were incubated with the substrate peptides for caspase-3 attached to p-nitroanilide (pNA) in buffer at $37^{\circ} \mathrm{C}$ for $2 \mathrm{~h}$. Finally, the absorbance at $405 \mathrm{~nm}$ was evaluated by a microplate reader (Bio-Rad Laboratories, Inc.).

Statistical analysis. All statistical analyses were determined with SPSS 22.0 software (IBM Corp.). The differences between two groups or among multi-groups were analyzed using an unpaired Student's t-test and one-way analysis of variance followed by Tukey's or Dunnett's post hoc test, respectively. The correlation between let-7b-5p and HMGA2 was analyzed by Pearson's correlation analysis. Data are shown as the mean \pm standard deviation of three independent repeats. $\mathrm{P}<0.05$ was considered to indicate a statistically significant difference.

\section{Results}

HMGA2 is downregulated in brain tissues of male PD mice and in $M P P^{+}$-treated SH-SY5Y cells. As shown in Fig. 1A and $\mathrm{B}, \mathrm{HMGA} 2 \mathrm{mRNA}$ and protein levels were significantly decreased in brain tissues of MPTP-treated male mice. Similarly, in $\mathrm{MPP}^{+}$-treated SH-SY5Y cells, HMGA2 expression was decreased in a concentration- and time-dependent manner (Fig. 1C-G).

HMGA2 overexpression suppresses the apoptosis of $\mathrm{MPP}^{+}$-treated SH-SY5Y cells. Next, the effect of HMGA2 on 
A



C


B



D

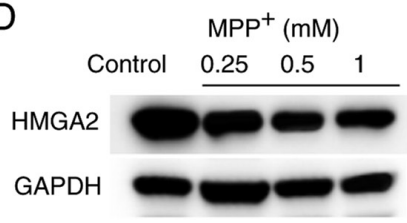

$\mathrm{F}$

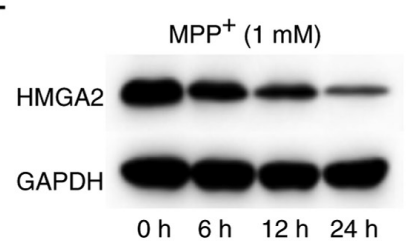



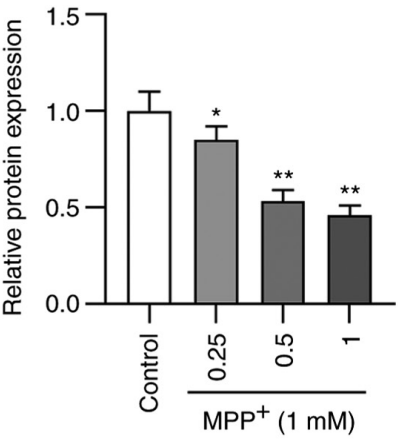

G

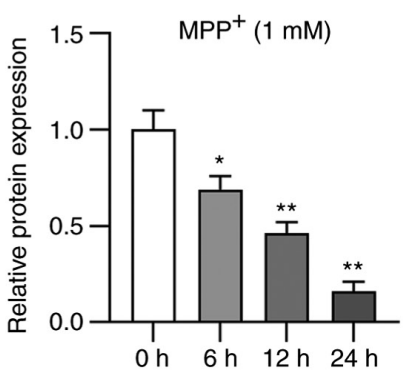

Figure 1. HMGA2 is downregulated in Parkinson's disease in vivo and in vitro. (A and B) RT-qPCR and western blotting were conducted to detect HMGA2 mRNA and protein levels in brain tissues of MPTP-treated mice ( $\mathrm{n}=6$ /group). (C and D) HMGA2 mRNA and protein levels in SH-SY5Y cells treated with $\mathrm{MPP}^{+}$at doses of $0.25,0.5$ and $1 \mathrm{mM}$ were determined by RT-qPCR and western blotting. (E-G) HMGA2 mRNA and protein levels in MPP+-treated SH-SY5Y cells after 6, 12 and $24 \mathrm{~h} .{ }^{*} \mathrm{P}<0.05,{ }^{* *} \mathrm{P}<0.01$ vs. normal, control or $0 \mathrm{~h}$ group. RT-qPCR, reverse transcription-quantitative PCR; HMGA2, high-mobility group AT-hook 2; MPTP, N-methyl-4-phenyl-1,2,3,6-tetrahydropyridine; MPP+, N-methyl-4-phenylpyridinium.

cell apoptosis was evaluated. At first, HMGA2 expression at the mRNA and protein levels was effectively overexpressed by transfection of pcDNA3.1/HMGA2 into $\mathrm{MPP}^{+}$-treated SH-SY5Y cells (Fig. 2A and B). Results from flow cytometry analysis indicated that $\mathrm{MPP}^{+}$treatment increased the apoptosis rate of SH-SY5Y cells, while HMGA2 overexpression partly reversed this effect (Fig. 2C and D). In addition, the number of TUNEL-positive cells was increased due to $\mathrm{MPP}^{+}$treatment, and then repressed by transfection of pcDNA3.1/HMGA2 (Fig. 2E). Moreover, $\mathrm{MPP}^{+}$treatment elevated the caspase-3 activity, while this effect was counteracted by overexpression of HMGA2 (Fig. 2F). Additionally, the $\mathrm{MPP}^{+}$-induced rise in Bax and decline in $\mathrm{Bcl}-2$ levels were neutralized by HMGA2 overexpression (Fig. 2G).

HMGA2 is targeted by let-7b-5p. According to the StarBase website, 10 miRNAs (hsa-let-7b-5p, hsa-let-7f-5p, hsa-miR-196b-5p, hsa-let-7d-5p, hsa-let-7i-5p, hsa-miR-4458, hsa-let-7a-5p, hsa-miR-196a-5p, hsa-let-7g-5p and hsa-let-7e-5p) were identified to target HMGA2 (Fig. 3A). As presented in Fig. 3B, let-7b-5p and miR-4458 were upregulated in response to $\mathrm{MPP}^{+}$treatment. Additionally, let-7b-5p has been widely reported to bind with HMGA2 (23-25), and can regulate the dysfunctions of neurons (11-13). Therefore, let-7b-5p was chosen for further exploration. As presented in Fig. 3C, let-7b-5p expression was upregulated in brain tissues of MPTP-treated male mice in a dose-dependent manner. Furthermore, it was found that the upregulation of let-7b-5p in $\mathrm{MPP}^{+}$-treated SH-SY5Y cells was in a time-dependent manner (Fig. 3D). In addition, Pearson's correlation analysis revealed that there was a very weak correlation between let-7b-5p expression and HMGA2 expression in brain tissues of MPTP-treated male mice (Fig. 3E). Furthermore, in response to let-7b-5p overexpression, let-7b-5p displayed a significant upregulation, while HMGA2 indicated a downregulation in $\mathrm{MPP}^{+}$group (Fig. 3F). Next, from the data of RIP assay, the abundant enrichment of let-7b-5p and HMGA2 was observed in Ago2 group rather than IgG group (Fig. 3G). Bioinformatics analysis revealed that let-7b-5p had a binding position on HMGA2 3'-UTR (Fig. 3H). In addition, the luciferase activity of HMGA2 3'-UTR -WT was markedly decreased in the let-7b-5p overexpression group (20 nM let-7b-5p mimics 


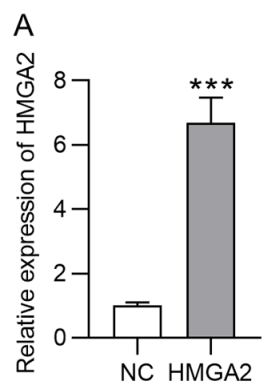

B



C
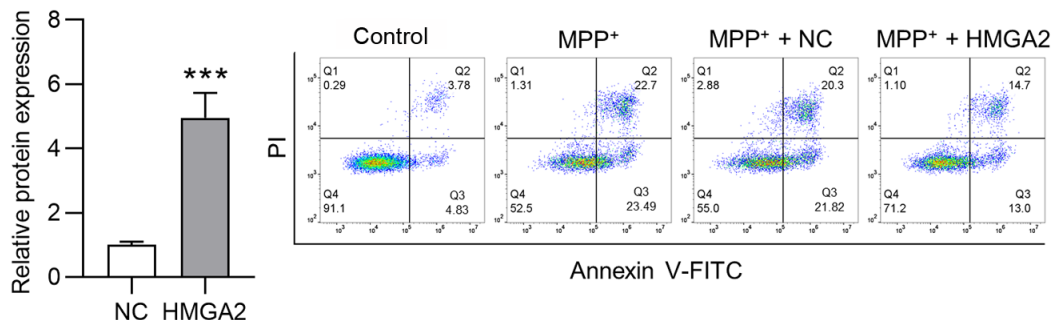

$\mathrm{E}$
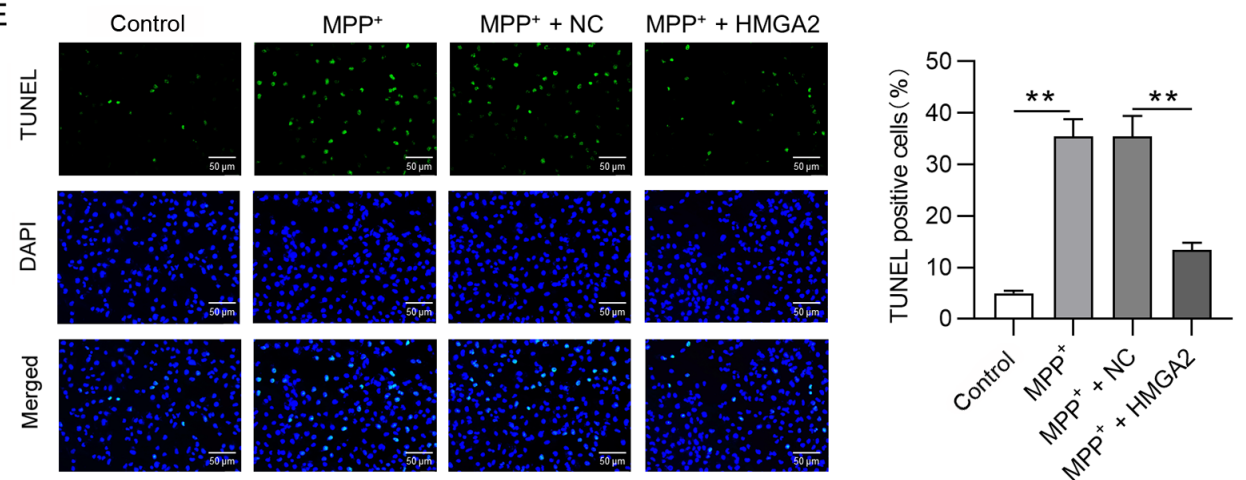

G


Figure 2. HMGA2 overexpression inhibits the apoptosis of MPP+-treated SH-SY5Y cells. (A and B) Overexpression efficiency of HMGA2 in MPP ${ }^{+}$-treated SH-SY5Y cells was determined by reverse transcription-quantitative PCR and western blot analysis. (C and D) Flow cytometry analysis detected the apoptosis of MPP+treated SH-SY5Y cells. (E) Number of TUNEL-positive cells was examined by TUNEL assay. Scale bar, $50 \mu \mathrm{m}$. (F) Caspase-3 activity in $\mathrm{MPP}^{+}$-treated SH-SY5Y cells was evaluated via a caspase-3 activity detection kit. (G) The Bax and Bcl-2 protein levels were tested by western blot analysis. ${ }^{*} \mathrm{P}<0.05,{ }^{* *} \mathrm{P}<0.01,{ }^{* * *} \mathrm{P}<0.001$ vs. control or NC group. HMGA2, high-mobility group AT-hook 2; MPP+, N-methyl-4-phenylpyridinium; TUNEL, terminal deoxynucleotidyl transferase-mediated dUTP nick end labeling; NC, negative control.

achieved the most notable effects) compared with that in the NC mimics group; however, the luciferase activity of HMGA2 3'-UTR-Mut remained the same in both groups (Fig. 3I). All the data demonstrated that HMGA2 was targeted by let-7b-5p.

Knockdown of let-7b-5p inhibits the apoptosis of $M P P^{+}$-induced SH-SY5Y cells. The specific function of let-7b-5p was then explored in MPP+-treated SH-SY5Y cells. To begin with, let-7b-5p was successfully knocked down by transfection of let-7b-5p inhibitor into $\mathrm{MPP}^{+}$-treated SH-SY5Y cells (Fig. 4A). Subsequently, it was found that the increased apoptosis rate of $\mathrm{MPP}^{+}$-treated SH-SY5Y cells was attenuated by let-7b-5p inhibitor (Fig. 4B). In addition, TUNEL assay revealed that knockdown of let-7b-5p partly reversed the increased number of TUNEL-positive cells arising from $\mathrm{MPP}^{+}$ treatment (Fig. 4C). Additionally, the caspase-3 activity was increased by $\mathrm{MPP}^{+}$treatment, but was rescued by transfection with let-7b-5p inhibitor (Fig. 4D). Moreover, the effects of
$\mathrm{MPP}^{+}$treatment on increased Bax and decreased Bcl-2 levels were counteracted by let-7b-5p inhibitor (Fig. 4E).

Let-7b-5p facilitates the apoptosis of $\mathrm{MPP}^{+}$-treated $\mathrm{SH}-\mathrm{SY} 5 \mathrm{Y}$ cells by targeting HMGA2. Subsequently, whether let-7b-5p regulates the apoptosis of $\mathrm{MPP}^{+}$-treated $\mathrm{SH}-\mathrm{SY} 5 \mathrm{Y}$ cells via targeting HMGA2 was probed. From the results of flow cytometric analysis, it was found that the let-7b-5p mimics-mediated increase in cell apoptosis was rescued by co-overexpression of let-7b-5p and HMGA2 (Fig. 5A). Likewise, the increase in TUNEL-positive cells resulting from let-7b-5p overexpression was reversed by co-transfection of let-7b-5p mimics and pcDNA3.1/HMGA2 (Fig. 5B). Furthermore, co-overexpression of let-7b-5p and HMGA2 reversed the promoting influence of let-7b-5p mimics on the caspase-3 activity (Fig. 5C). Moreover, the impacts of let-7b-5p mimics on the protein levels of Bax and Bcl-2 were rescued by the co-overexpression of let-7b-5p and 

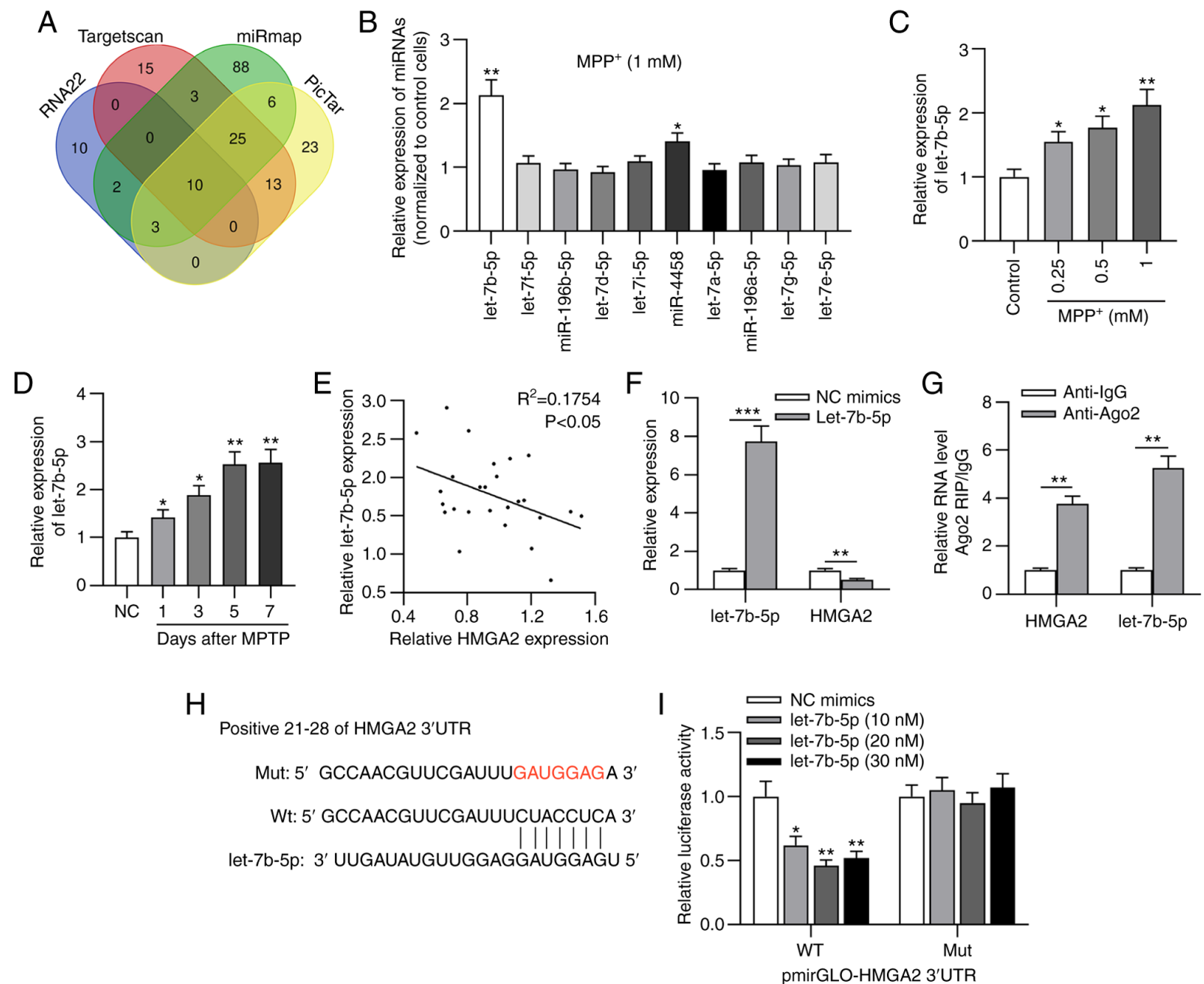

Figure 3. HMGA2 is a downstream target of let-7b-5p. (A) Prediction of potential miRNAs possessing binding sites on HMGA2 3'UTR. (B) Expression of 10 miRNAs in MPP+treated SH-SY5Y cells. "P<0.05, " $\mathrm{P}<0.01$ vs. basal cells without MPP+ stimulation. (C and D) RT-qPCR evaluated let-7b-5p levels in brain tissues of PD mice ( $\mathrm{n}=6 /$ group) and in MPP+-intoxicated SH-SY5Y cells. (E) Pearson's correlation analysis indicated the negative correlation between HMGA2 and let-7b-5p expression in the brain tissues of PD mice ( $\mathrm{n}=24$ ). (F) RT-qPCR was used to measure let-7b-5p and HMGA2 levels in MPP+-intoxicated SH-SY5Y cells in response to let-7b-5p mimics. (G) A radioimmunoprecipitation assay was used to assess the binding possibility between HMGA2 and let-7b-5p. (H) Bioinformatics analysis (http://www. targetscan.org/vert_72/) revealed the potential binding sites between let-7b-5p and HMGA2. (I) A luciferase reporter assay was performed to evaluate the binding possibility of HMGA2 and let-7b-5p. ${ }^{*} \mathrm{P}<0.05,{ }^{* * *} \mathrm{P}<0.01,{ }^{* * *} \mathrm{P}<0.001$ vs. control or NC group. HMGA2, high-mobility group AT-hook 2; PD, Parkinson's disease; $\mathrm{MPP}^{+}$, N-methyl-4-phenylpyridinium; NC, negative control; UTR, untranslated region; miRNAs, microRNAs; RT-qPCR, reverse transcription-quantitative PCR; WT, wild-type; Mut, mutant.

HMGA2 (Fig. 5D). Importantly, overexpressing HMGA2 open reading frame linked with 3'UTR had no rescue effects on let-7b-5p-mediated cell apoptosis (Fig. 5A and D).

\section{Discussion}

A previous study reported that the pathogenesis of PD is associated with neuronal apoptosis resulting from impaired mitochondrial function (26). MPTP is a widely used mitochondrial complex I inhibitor and selectively damages dopaminergic neurons in SNpc (27). MPTP can cross the blood-brain barrier, enter the brain, and then produce active $\mathrm{MPP}^{+}$, a dopamine neuron toxicant, which decreases mitochondrial energy metabolism, facilitates ROS release and results in cell apoptosis $(28,29)$. Thus, MPTP and $\mathrm{MPP}^{+}$are often applied in in vivo and in vitro models, respectively. In the present study, male mice were treated with MPTP and SH-SY5Y cells were treated with $\mathrm{MPP}^{+}$to investigate the role and function of HMGA2 in in vivo and in vitro models of PD. Previously, HMGA2 was proposed to regulate the proliferation of neural progenitors (30). In addition, HMGA2 was reported to control the neural stem cell differentiation and aging (17). During aging, downregulated HMGA2 results in the dysfunction of neural stem cells (17,31). In the present study, HMGA2 was identified to be downregulated in brain tissues of male PD mice and in MPP ${ }^{+}$-treated SH-SY5Y cells. Moreover, HMGA2 was indicated to inhibit neurite outgrowth of primary cortical neurons (32). The present study revealed that HMGA2 overexpression inhibited the apoptosis of $\mathrm{MPP}^{+}$-treated SH-SY5Y cells.

Increasing number of reports indicated that miRNAs regulate the development of PD. For instance, miR-30b inhibits the apoptosis of nigrostriatal dopaminergic neurons in PD models by targeting SNCA (33). miR-29c-3p inactivates microglial NLRP3 inflammasome in PD via the regulation of NFAT5 expression (34). Suppression on miR-301b-3p decreases 
A



C
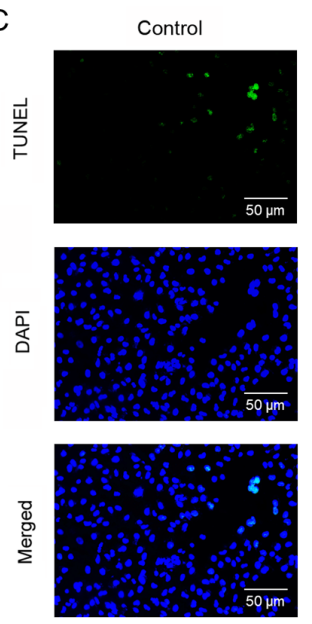

D

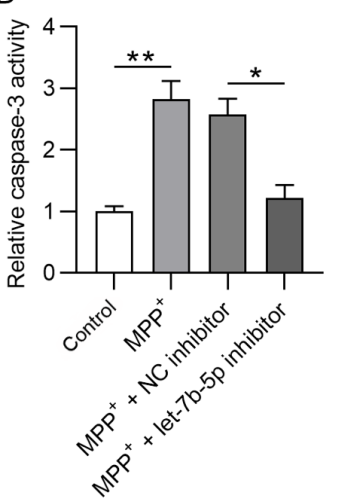

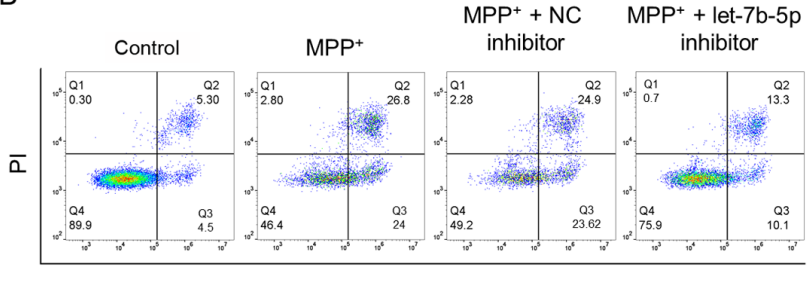

Annexin V-FITC
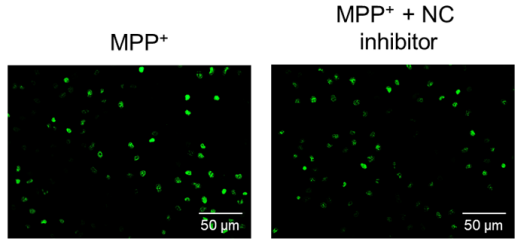

$\mathrm{MPP}^{+}+$let-7b-5p
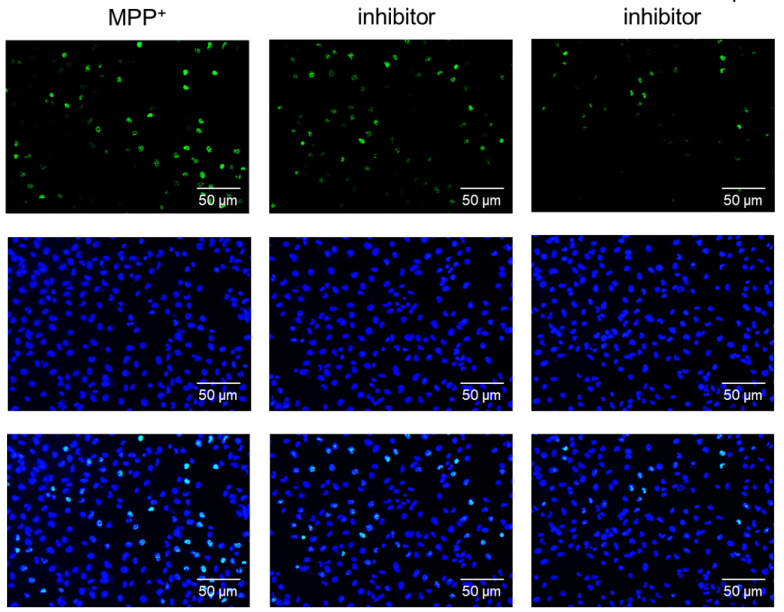

$E$

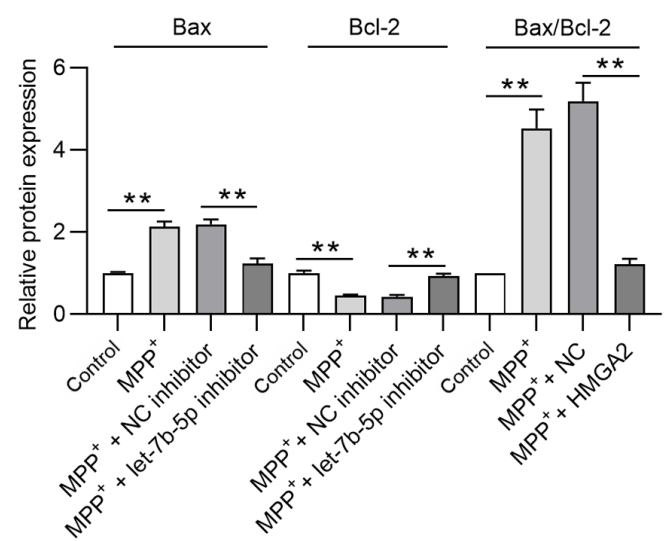

Figure 4. Knockdown of let-7b-5p inhibits the apoptosis of MPP+-treated SH-SY5Y cells. (A) Knockdown efficiency of let-7b-5p in MPP+-treated SH-SY5Y cells was determined by reverse transcription-quantitative PCR. (B and C) Cell apoptosis was assessed by flow cytometry and TUNEL assays. Scale bar, $50 \mu \mathrm{m}$. (D) Relative caspase-3 activity was evaluated via a caspase-3 activity detection kit. (E) Bax and Bcl-2 protein levels were tested by western blot analysis. ${ }^{*} \mathrm{P}<0.05,{ }^{* *} \mathrm{P}<0.01,{ }^{* * * *} \mathrm{P}<0.001$. MPP ${ }^{+}, \mathrm{N}$-methyl-4-phenylpyridinium; NC, negative control; TUNEL, terminal deoxynucleotidyl transferase-mediated dUTP nick end labeling.

dopaminergic neuron loss in PD (35). Bioinformatics analysis showed several miRNAs that have potential binding sites for HMGA2. Importantly, numerous studies proposed that let-7b-5p directly binds with HMGA2 in a variety of cells to influence biological processes $(18,24,25,31)$. Therefore, let-7b-5p was chosen for further exploration. In the present study, let-7b-5p level was downregulated in MPTP-treated male mice and $\mathrm{MPP}^{+}$-treated $\mathrm{SH}-\mathrm{SY} 5 \mathrm{Y}$ cells. In addition, HMGA2 was directly targeted by let-7b-5p at the 3'UTR. Its expression was negatively correlated with let-7b-5p expression in brain tissues of male PD mice. Let-7b-5p inhibited the
mRNA expression of HMGA2, and further decreased its translation. Recently, let-7b-5p was confirmed to serve as a potential biomarker for ischemic stroke, Parkinsonian syndromes and Alzheimer's disease (11-13). Importantly, let-7b-5p can facilitate neuronal degeneration and cause neurotoxicity (36). In the present study, knockdown of let-7b-5p inhibited the apoptosis of $\mathrm{MPP}^{+}$-intoxicated SH-SY5Y cells. Rescue assays illustrated that let-7b-5p suppressed the apoptosis of SH-SY5Y cells in PD by targeting HMGA2.

In conclusion, the present study demonstrated that let-7b-5p facilitates cell apoptosis in PD by targeting HMGA2, which 

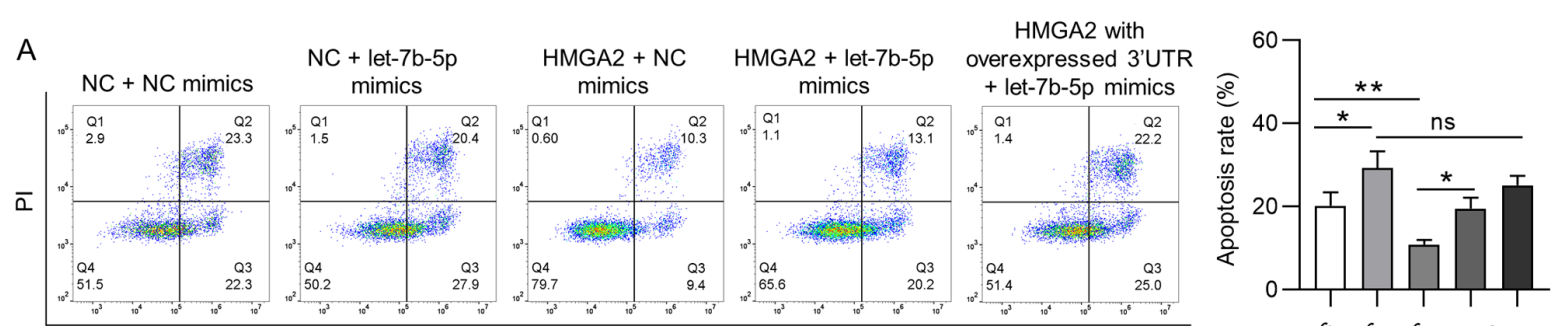

Annexin V-FITC

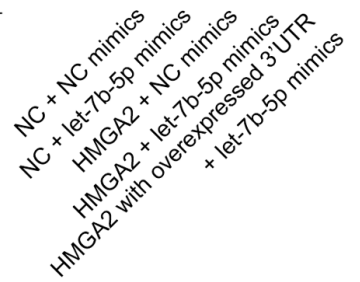

B $\mathrm{NC}+\mathrm{NC}$ mimics



mimics
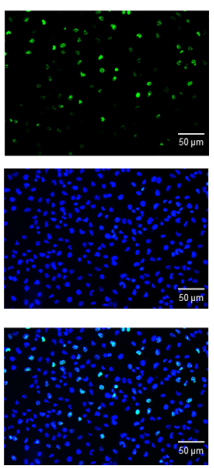

$\mathrm{HMGA} 2+\mathrm{NC}$
mimics
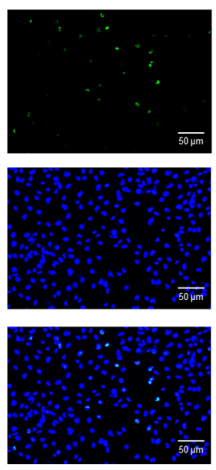

HMGA2 with HMGA2 + let-7b-5p overexpressed 3'UTR mimics
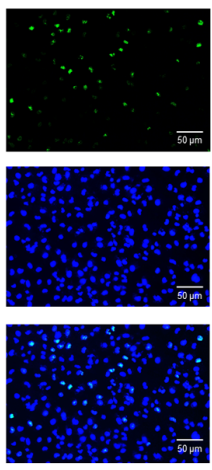
+ let-7b-5p mimics



C

D
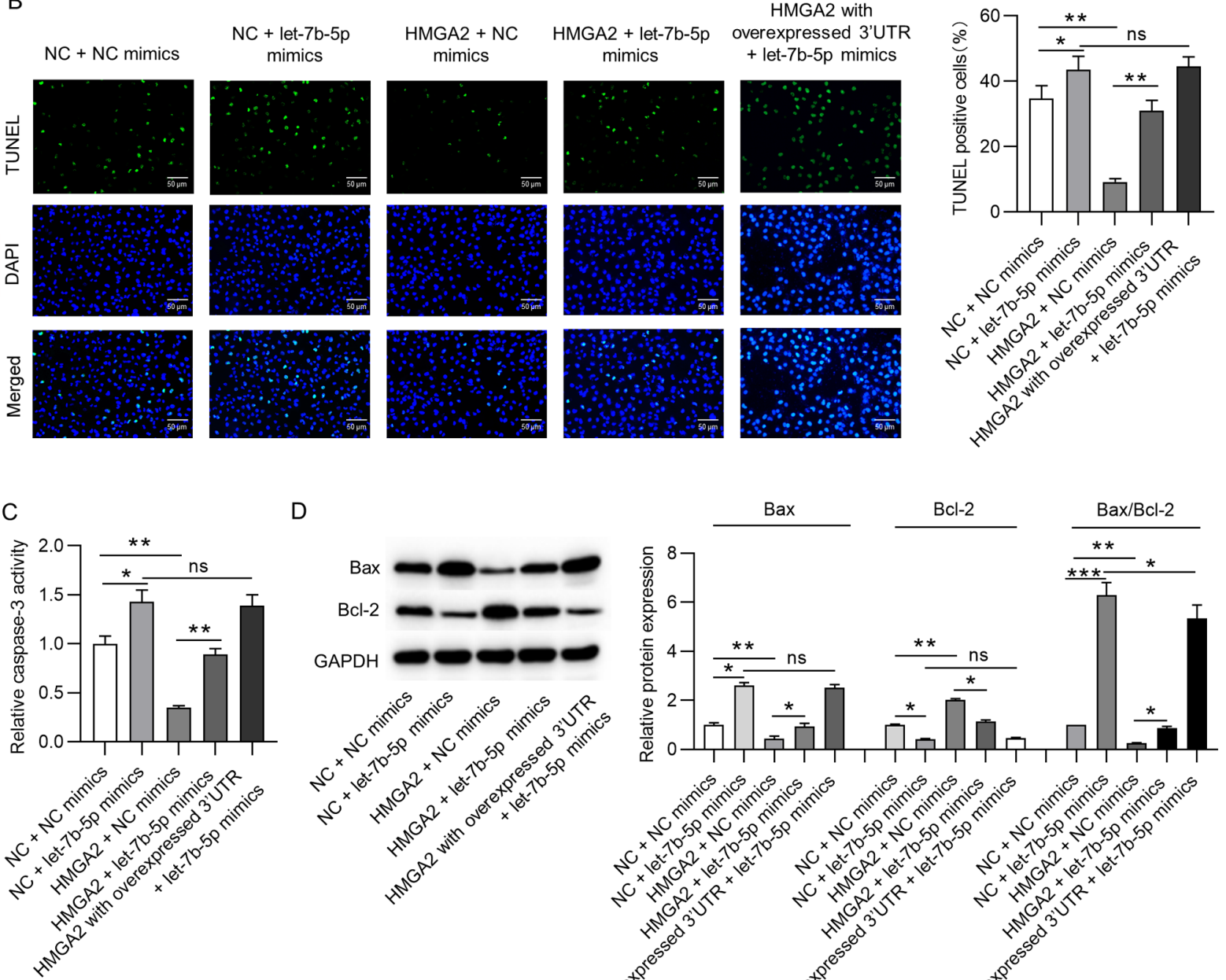

Bcl-2
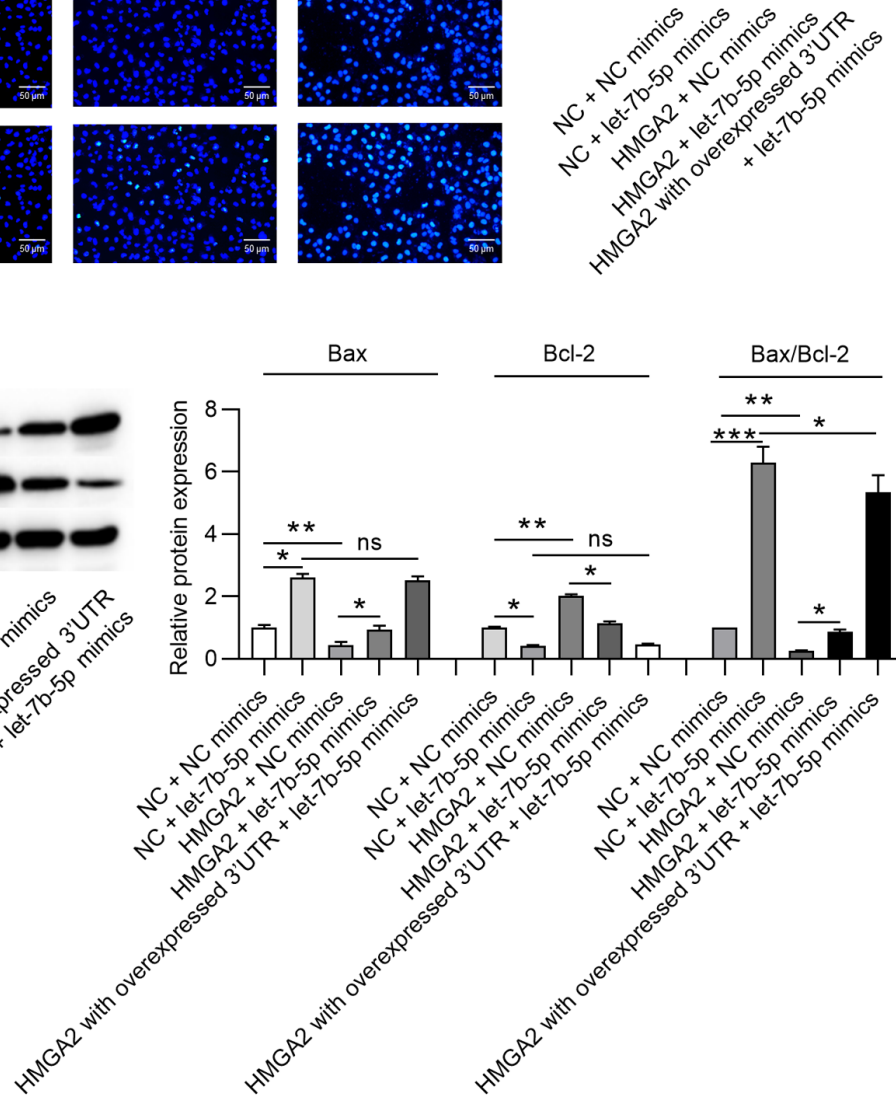

in 2 is


Figure 5. Let-7b-5p promotes the apoptosis of MPP+-treated SH-SY5Y cells by targeting HMGA2. (A and B) Cell apoptosis was evaluated by flow cytometry and TUNEL assays in indicated groups: NC + NC mimics; NC + let-7b-5p mimics; HMGA2 + NC mimics; HMGA2 + let-7b-5p mimics; HMGA2 with overexpressed 3'UTR + let-7b-5p mimics. Scale bar, $50 \mu \mathrm{m}$. (C) Relative caspase-3 activity was evaluated via a caspase-3 activity detection kit in indicated groups: NC + NC mimics; NC + let-7b-5p mimics; HMGA2 + NC mimics; HMGA2 + let-7b-5p mimics; HMGA2 with overexpressed 3'UTR + let-7b-5p mimics. (D) Bax and Bcl-2 protein levels were tested by western blot analysis in indicated groups: $\mathrm{NC}+\mathrm{NC}$ mimics; $\mathrm{NC}+$ let-7b-5p mimics; HMGA2 + NC mimics; HMGA2 + let-7b-5p mimics; HMGA2 with overexpressed 3'UTR + let-7b-5p mimics. ${ }^{*} \mathrm{P}<0.05,{ }^{* *} \mathrm{P}<0.01,{ }^{* * *} \mathrm{P}<0.001$. ns, no significance; HMGA2, high-mobility group AT-hook 2; $\mathrm{MPP}^{+}, \mathrm{N}$-methyl-4-phenylpyridinium; UTR, untranslated region; NC, negative control; TUNEL, terminal deoxynucleotidyl transferase-mediated dUTP nick end labeling.

offers a potential theoretical basis for the study of effective therapy in PD. Some limitations of the present study must be acknowledged. First, only male animals were used in the study, while the effects of sex difference cannot be excluded. Secondly, let-7b-5p might directly or indirectly affect the expression of HMGA2 by other mechanisms, which needs 
further investigation in future studies. Furthermore, functions of let-7b-5p and HMGA2 in vivo need to be further explored.

\section{Acknowledgements}

Not applicable.

\section{Funding}

No funding was received.

\section{Availability of data and materials}

The datasets used and/or analyzed during the present study are available from the corresponding author on reasonable request.

\section{Authors' contributions}

YH designed the experiments. YH, YL, JH, ZW, LW, LF and LG performed the experiments. YH, ZW, LW and LF analyzed the data. YH wrote the paper. YH, YL and ZW contributed to data interpretation and manuscript revision. YH and YL confirm the authenticity of all the raw data. All authors read and approved the final manuscript.

\section{Ethics approval and consent to participate}

The animal experiments were conducted based on the protocols from Research Committee, and the study was authorized by the Institutional Animal Care and Use Committee of Taizhou People's Hospital (approval no. 2019-004; Jiangsu, China).

\section{Patient consent for publication}

Not applicable.

\section{Competing interests}

The authors declare that they have no competing interests.

\section{References}

1. Tysnes OB and Storstein A: Epidemiology of Parkinson's disease. J Neural Transm (Vienna) 124: 901-905, 2017.

2. Michely J, Volz LJ, Barbe MT, Hoffstaedter F, Viswanathan S, Timmermann L, Eickhoff SB, Fink GR and Grefkes C: Dopaminergic modulation of motor network dynamics in Parkinson's disease. Brain 138: 664-678, 2015.

3. Picillo M, Erro R, Amboni M, Longo K, Vitale C, Moccia M, Pierro A, Scannapieco S, Santangelo G, Spina E, et al: Gender differences in non-motor symptoms in early Parkinson's disease: A 2-years follow-up study on previously untreated patients. Parkinsonism Relat Disord 20: 850-854, 2014.

4. Baldereschi M, Di Carlo A, Rocca WA, Vanni P, Maggi S, Perissinotto E, Grigoletto F, Amaducci L and Inzitari D ILSA Working Group. Italian Longitudinal Study on Aging: Parkinson's disease and parkinsonism in a longitudinal study: Two-fold higher incidence in men. Neurology 55: 1358-1363, 2000.

5. Rodriguez-Oroz MC, Jahanshahi M, Krack P, Litvan I, Macias R, Bezard E and Obeso JA: Initial clinical manifestations of Parkinson's disease: Features and pathophysiological mechanisms. Lancet Neurol 8: 1128-1139, 2009.

6. Carvey PM, Punati A and Newman MB: Progressive dopamine neuron loss in Parkinson's disease: The multiple hit hypothesis. Cell Transplant 15: 239-250, 2006.
7. Ascherio A and Schwarzschild MA: The epidemiology of Parkinson's disease: Risk factors and prevention. Lancet Neurol 15: 1257-1272, 2016.

8. Charvin D, Medori R, Hauser RA and Rascol O: Therapeutic strategies for Parkinson disease: Beyond dopaminergic drugs. Nat Rev Drug Discov 17: 804-822, 2018.

9. Bartel DP: MicroRNAs: Genomics, biogenesis, mechanism, and function. Cell 116: 281-297, 2004.

10. Zou X, Kang L, Yang M, Wu J and Guan H: MicroRNA binding mediated functional sequence variant in 3'-UTR of DNA repair Gene XPC in Age-related Cataract. Sci Rep 8: 15198, 2018.

11. Rahman MR, Islam T, Zaman T, Shahjaman M, Karim MR, Huq F, Quinn JMW, Holsinger RMD, Gov E and Moni MA: Identification of molecular signatures and pathways to identify novel therapeutic targets in Alzheimer's disease: Insights from a systems biomedicine perspective. Genomics 112: 1290-1299, 2020.

12. Starhof C, Hejl AM, Heegaard NHH, Carlsen AL, Burton M, Lilje B and Winge K: The biomarker potential of cell-free microRNA from cerebrospinal fluid in Parkinsonian Syndromes. Mov Disord 34: 246-254, 2019.

13. Chi NF, Chiou HY, Chou SY, Hu CJ, Chen KY, Chang CF and Hsieh YC: Hyperglycemia-related FAS gene and hsa-let-7b-5p as markers of poor outcomes for ischaemic stroke. Eur J Neurol 27: 1647-1655, 2020.

14. Kang R, Chen R, Zhang Q, Hou W, Wu S, Cao L, Huang J, Yu Y, Fan XG, Yan Z, et al: HMGB1 in health and disease. Mol Aspects Med 40: 1-116, 2014.

15. Chau KY, Patel UA, Lee KL, Lam HY and Crane-Robinson C: The gene for the human architectural transcription factor HMGI-C consists of five exons each coding for a distinct functional element. Nucleic Acids Res 23: 4262-4266, 1995.

16. Ashar HR, Fejzo MS, Tkachenko A, Zhou X, Fletcher JA, Weremowicz S, Morton CC and Chada K: Disruption of the architectural factor HMGI-C: DNA-binding AT hook motifs fused in lipomas to distinct transcriptional regulatory domains. Cell 82: 57-65, 1995.

17. Nishino J, Kim I, Chada K and Morrison SJ: Hmga2 promotes neural stem cell self-renewal in young but not old mice by reducing p16Ink4a and p19Arf Expression. Cell 135: 227-239, 2008.

18. Patterson M, Gaeta X, Loo K, Edwards M, Smale S, Cinkornpumin J, Xie Y, Listgarten J, Azghadi S, Douglass SM, et al: let-7 miRNAs can act through notch to regulate human gliogenesis. Stem Cell Reports 3: 758-773, 2014.

19. Vukicevic V, Jauch A, Dinger TC, Gebauer L, Hornich V, Bornstein SR, Ehrhart-Bornstein M and Müller AM: Genetic instability and diminished differentiation capacity in long-term cultured mouse neurosphere cells. Mech Ageing Dev 131: 124-132, 2010

20. Stein JL, Medland SE, Vasquez AA, Hibar DP, Senstad RE, Winkler AM, Toro R, Appel K, Bartecek R, Bergmann Ø, et al; Alzheimer's Disease neuroimaging initiative; EPIGEN Consortium; IMAGEN Consortium; Saguenay Youth Study Group; Cohorts for Heart and Aging Research in Genomic Epidemiology Consortium; Enhancing Neuro Imaging Genetics through Meta-Analysis Consortium: Identification of common variants associated with human hippocampal and intracranial volumes. Nat Genet 44: 552-561, 2012.

21. Tang L, Liu L, Li G, Jiang P, Wang Y and Li J: Expression profiles of long noncoding RNAs in intranasal LPS-mediated Alzheimer's disease model in mice. BioMed Res Int 2019: 9642589, 2019.

22. Livak KJ and Schmittgen TD: Analysis of relative gene expression data using real-time quantitative PCR and the 2(-Delta Delta C(T)) method. Methods 25: 402-408, 2001.

23. Di Fazio P, Maass M, Roth S, Meyer C, Grups J, Rexin P, Bartsch DK and Kirschbaum A: Expression of hsa-let-7b-5p, hsa-let-7f-5p, and hsa-miR-222-3p and their putative targets HMGA 2 and CDKN1B in typical and atypical carcinoid tumors of the lung. Tumour Biol 39: 1010428317728417, 2017.

24. Li S, Peng F, Ning Y, Jiang P, Peng J, Ding X, Zhang J, Jiang $\mathrm{T}$ and Xiang S: SNHG16 as the miRNA let-7b-5p sponge facilitates the G2/M and epithelial-mesenchymal transition by regulating $\mathrm{CDC} 25 \mathrm{~B}$ and HMGA2 expression in hepatocellular carcinoma. J Cell Biochem 121: 2543-2558, 2020.

25. Li X, Sun M and Long Y: Cyanidin-3-O-glucoside attenuates lipopolysaccharide-induced inflammation in human corneal epithelial cells by inducing Let-7b-5p-Mediated HMGA2/ PI3K/Akt pathway. Inflammation 43: 1088-1096, 2020. 
26. Ouazia D, Levros LC Jr, Rassart É and Desrosiers RR: The protein l-isoaspartyl (d-aspartyl) methyltransferase protects against dopamine-induced apoptosis in neuroblastoma SH-SY5Y cells. Neuroscience 295: 139-150, 2015.

27. $\mathrm{Yi} \mathrm{F}, \mathrm{He} \mathrm{X}$ and Wang D: Lycopene protects against MPP(+)-induced cytotoxicity by maintaining mitochondrial function in SH-SY5Y cells. Neurochem Res 38: 1747-1757, 2013.

28. Dauer W and Przedborski S: Parkinson's disease: Mechanisms and models. Neuron 39: 889-909, 2003.

29. Suzuki K, Mizuno Y and Yoshida M: Effects of 1-methyl4-phenyl-1,2,3,6-tetrahydropyridine (MPTP)-like compounds on mitochondrial respiration. Adv Neurol 53: 215-218, 1990.

30. Zhou X, Zhong S, Peng H, Liu J, Ding W, Sun L, Ma Q, Liu Z, Chen R, Wu Q, et al: Cellular and molecular properties of neural progenitors in the developing mammalian hypothalamus. Nat Commun 11: 4063, 2020.

31. Tzatsos A and Bardeesy N: Ink4a/Arf regulation by let-7b and Hmga2: A genetic pathway governing stem cell aging. Cell Stem Cell 3: 469-470, 2008.

32. Bhuiyan MIH, Kim SY and Cho KO: Lin28 overexpression inhibits neurite outgrowth of primary cortical neurons in vitro. Acta Neurobiol Exp (Warsz) 78: 297-304, 2018.
33. Shen YF, Zhu ZY, Qian SX, Xu CY and Wang YP: miR-30b protects nigrostriatal dopaminergic neurons from MPP(+)-induced neurotoxicity via SNCA. Brain Behav 10: e01567, 2020

34. Wang R, Li Q, He Y, Yang Y, Ma Q and Li C: miR-29c-3p inhibits microglial NLRP3 inflammasome activation by targeting NFAT5 in Parkinson's disease. Genes Cells 25: 364-374, 2020.

35. Jiang J, Piao X, Hu S, Gao J and Bao M: LncRNA H19 diminishes dopaminergic neuron loss by mediating microRNA-301b-3p in Parkinson's disease via the HPRT1-mediated Wnt/ $\beta$-catenin signaling pathway. Aging (Albany NY) 12: 8820-8836, 2020.

36. Chavoshi H, Boroujeni ME, Abdollahifar MA, Amini A, Tehrani AM, Moghaddam MH, Norozian M, Farahani RM and Aliaghaei A: From dysregulated microRNAs to structural alterations in the striatal region of METH-injected rats. J Chem Neuroanat 109: 101854, 2020.

This work is licensed under a Creative Commons Attribution-NonCommercial-NoDerivatives 4.0 International (CC BY-NC-ND 4.0) License. 